\title{
Alphabetism and the science of reading: from the perspective of the akshara languages
}

\author{
Sonali $\mathrm{Nag}^{1,2 *}$ \\ ${ }^{2}$ Department of Experimental Psychology, University of Oxford, Oxford, UK \\ ${ }^{*}$ Correspondence: sonalinag@t-p-f.org \\ Edited by: \\ Claire Marie Fletcher-Flinn, University of Otago, New Zealand \\ Reviewed by: \\ Prakash Padakannaya, University of Mysore, India
}

1 Early Childhood and Primary School Programmes, The Promise Foundation, Bangalore, India

Keywords: akshara, orthographic processing, cross-linguistic, alphasyllabary, hindi

\section{A commentary on}

Alphabetism in reading science

by Share, D. L. (2014). Front. Psychol. 5:752. doi: 10.3389/fpsyg.2014.00752

An interesting area of enquiry in reading science is the ways in which different writing systems represent language. Discussions have centered around the adaptations seen between writing systems and languages (Perfetti and Harris, 2013) and the related notions of deservedness of a writing system for a language (Halliday, 1977), optimality (Frost, 2012) and level of orthography-language or "grapholinguistic" equilibrium (Seidenberg, 2011). Among the many ideas of relative goodness of writing systems is also a misplaced superiority assigned to alphabet-based orthographies, which has been critically labeled as "alphabetism" (Share, 2014). Share counters the superiority claim with psychoacoustic, historic, anthropological and preliminary experimental evidence to show that syllable-based writing systems are perhaps the better system, at least for some aspects of the orthography-language relationship. The defining parameters for placing symbol systems in a hierarchy are however, as yet, unclear (see Frost, 2012 for a discussion). It is for this very reason that reading research (and the practice it influences) must be alert to unqualified generalizations made from studies conducted in a single writing system. Evidence from robust cross-orthographic experimentation is the best moderator of such universalism. The burgeoning body of work from the Chinese languages has for example broadened the field, and perhaps snuffed out "alphabetism" in some domains (e.g., neural bases of reading and the preferred ordering of symbols as linear: Perfetti et al., 2010). Some insights are now also available from experimental work and surveys in Japanese Hiragana (e.g., FletcherFlinn et al., 2014). More recently, research in the Indic alphasyllabaries highlights the role of orthography-specific investigations in the quest for a more inclusive reading science (Nag, 2007, 2014).

The orthographies of South and Southeast Asia descend from the ancient script of Brahmi and together may be referred to as the Indic alphasyllabaries. The symbol unit of these orthographies is the akshara. The surface organization of each unit is typically a symbol block with one or more phonemic markers. An akshara may represent a vowel $(/ \mathrm{V} /)$, a consonant $(/ \mathrm{C} /)$, a consonant with the inherent vowel /a/ or other marked vowels (/Ca/, /CV/), and consonant clusters with either the inherent or marked vowels (e.g., $/ \mathrm{CCa} /, / \mathrm{CCV} /$, /CCCV/). The mapping of word level phonology to specific akshara is decided by a rule of re-syllabification where post-vocalic consonants form the next akshara. To illustrate with number names from the Indo-Aryan language of Hindi, the akshara in shunya (zero) follow the rule of re-syllabification with the second akshara formed by a coda-open syllable concatenation (शुन्य, <CV.CCa $>$ "shu.nya," the coda of the first syllable is pinned to the next syllable to make the symbol block "nya"). The transcription in the akshara system is typically complete, though mapping to phonology is variable. For example, nau (nine) represents an open syllable (नौ, $\langle\mathrm{CV}>$, "nau"), das (10) a body and coda (दस, $<\mathrm{CV}^{\circ} \mathrm{C}^{\circ}>$, "da.s"), and gyaarah (11) an open syllable, a body and a coda (ग्यारह, <CCV.Ca. ${ }^{\circ}>$, "gyaa.ra.h"). There are further conditional rules in Hindi such as vowel suppression where the akshara-to-phonology representation becomes somewhat opaque. Thus, in bees, thees, and chalees $(20,30$, and 40) the word-final /s/ is written with an akshara carrying the inherent vowel /a/ but this vowel is suppressed in pronunciation (i.e., $<\mathrm{C}^{\circ}>$ ), thus बीस and तीस, $\left\langle\mathrm{CV} . \mathrm{C}^{\circ}\right\rangle$, and चालीस, $\left.<\mathrm{CV} . \mathrm{CV} . \mathrm{C}^{\circ}\right\rangle$. Similar schwa suppression is also seen in the earlier examples, das and gyaarah.

Akshara-based orthographies such as Bengali, Gujarati, Lao, Tamil, and Sinhala each have similarly well-defined orthographic principles. Whereas in other phonologically-based writing systems like the alphabet and the abjad, the orthographic representation of one particular sub-lexical level predominates, the mapping to phonology in the akshara-based orthographies is defined by context. If appearing single, then the akshara is typically an orthographic syllable, but if in a string, language-specific rules delimit orthographic representation. Thus, akshara units map to multiple levels of phonology. Given the current state of the science, this psycholinguistic design of the akshara requires greater examination. But what should be immediately clear is that the pre-eminence given to the phoneme in several accounts of orthographic representation (e.g., Katz and Frost, 1992; Ziegler and Goswami, 
2005) is an alphabet-centric model. The akshara based psycholinguistic tradition has instead drawn upon the role of orality in literacy development (Patel and Soper, 1987; Patel, 1996, 2004), the articulatory features of single akshara and word-level prosody (Pandey, 2007, 2014), the nature and scope of akshara-language mapping (Sircar and Nag, 2013; Nag, 2014), the cognitive bases of reading acquisition (Prakash et al., 1993; Nag and Snowling, 2012) and the profiles of impairment in adult clinical conditions (Karanth, 2002). What is needed for a universal theory of reading (and spelling) development is a delineation of the cognitive-linguistic mechanisms associated with a writing system that has the facility for multiple levels of sub-lexical representation. Constructs that have shown promise include syllable weight and the mora. These constructs pick out the regularities in spelling-sound mapping and hence may be the principle that makes learning of the orthographylanguage connections secure. Ideas about syllable weight and the mora have deep roots in linguistic science but are yet to inform discourse in the reading science.

The symbol set is another case in point. The number of letters in alphabet-based systems is small, and symbol learning is completed within the first year of instruction. In contrast to the small set or a contained orthography, are systems with several thousand symbols. The characters for a Chinese language such as Mandarin is one example of an extensive orthography. In the Indic alphasyllabaries, the number of akshara that can be hypothetically constructed also run into thousands, with two constraints defining the learning space. First, a manageable set of consonant and vowel phonemic markers aid akshara construction, bringing economy to the learning task. Second, the number of akshara that are phonotactically implausible are far more in number, although the number that are in use and hence encountered in print still runs into hundreds. Not surprisingly, a corollary of an extensive symbol set is that symbol learning continues well into middle school and beyond. If the received wisdom is that children typically always know the alphabet by the end of the first year then it is not hard to see how the pace of learning in the extensive orthographies might be perceived. "Slow" learning then becomes one reason to invoke "alphabetism," with suggestions that the local orthographies are too difficult for fast paced literacy learning.

Furthermore, a comprehensive theory of literacy learning will have to factor in the learning mechanisms involved in the akshara languages, particularly the role of domains such as visual memory, morphology and syntax, and several other aspects of the orthography. Some of these include non-linear symbol arrangements (Vaid and Gupta, 2002; Kandhadai and Sproat, 2010; Winskel and Perea, 2014), unmarked and inherent symbol features (Nag, 2007; Bhide et al., 2014), visually complex symbol sets (Nag et al., 2014) and word types differing because of symbol characteristics (Nag, 2014; Wijayathilake and Parrila, 2014) or morpho-orthographic characteristics (Rao et al., 2012). A step before the hunt for higher-order universals would be to bring focus in reading science on these kinds of particularities.

\section{ACKNOWLEDGMENT}

The author would like to thank Purushottam G. Patel and Margaret J. Snowling for their comments on previous versions of this commentary.

\section{REFERENCES}

Bhide, A., Gadgil, S., Zelinsky, C. M., and Perfetti, C. (2014). Does reading in an alphasyllabary affect phonemic awareness? Inherent schwa effects in Marathi-English bilinguals. Writ. Syst. Res. 6, 73-93. doi: 10.1080/17586801.2013.855619

Fletcher-Flinn, C. M., Thompson, G. B., Yamada, M., and Meissel, K. (2014). Learning of a formation principle for the secondary phonemic function of a syllabic orthography. Read. Writ. 27, 875-904. doi: 10.1007/s11145-013-9473-0

Frost, R. (2012). Towards a universal model of reading. Behav. Brain Sci. 35, 263-329. doi: 10.1017/S0140525X11001841

Halliday, M. A. K. (1977). "Ideas about language," in Aims and Perspectives in Linguistics. Occasional Papers, No. I (Applied Linguistics Association of Australia), 32-55.

Kandhadai, P., and Sproat, R. (2010). Impact of spatial ordering of graphemes in alphasyllabic scripts on phonemic awareness in Indic languages. Writ. Syst. Res. 2, 105-116. doi: 10.1093/wsr/wsq009

Karanth, P. (2002). Reading into reading research through nonalphabetic lenses. Top. Lang. Disord. 22, 20-31. doi: 10.1097/00011363-20021100000006

Katz, L., and Frost, R. (1992). "The reading process is different for different orthographies: the orthographic depth hypothesis," in Orthography, Phonology, Morphology, and Meaning: Advances in Psychology, Vol. 94, eds R. Frost and L. Katz (North Holland: Elsevier), 67-84.
Nag, S. (2007). Early reading in Kannada: the pace of acquisition of orthographic knowledge and phonemic awareness. J. Res. Read. 30, 7-22. doi: 10.1111/ j.1467-9817.2006.00329.x

Nag, S. (2014). Akshara-phonology mappings: the common yet uncommon case of the consonant cluster. Writ. Syst. Res. 6, 105-119. doi: 10.1080/ 17586801.2013.855621

Nag, S., and Snowling, M. J. (2012). Reading in an alphasyllabary: implications for a languageuniversal theory of learning to read. Sci. Stud. Read. 16, 404-423. doi: 10.1080/10888438.2011. 576352

Nag, S., Snowling, M., Quinlan, P., and Hulme, C. (2014). Child and symbol factors in learning to read a visually complex writing system. Sci. Stud. Read. 18, 1-16. doi: 10.1080/10888438.2014. 892489

Pandey, P. (2014). Akshara-to-sound rules for Hindi. Writ. Syst. Res. 6, 54-72. doi: 10.1080/17586801.2013.855622

Pandey, P. K. (2007). "Akshara as the minimum articulatory unit," in The Indic Scripts: Palaeographic and Linguistic Perspectives, eds P. G. Patel, P. Pandey, and D. Rajgor (New Delhi: DK Printworld), 167-232.

Patel, P. G. (1996). Linguistic and cognitive aspects of the Orality-Literacy complex in Ancient India. Lang. Commun. 16, 315-329.

Patel, P. G. (2004). Reading Acquisition in India: Models of Learning and Dyslexia. New Delhi: Sage Publishers.

Patel, P. G., and Soper, H. V. (1987). Acquisition of reading and spelling in a syllabo-alphabetic writing system. Lang. Speech 30, 69-81.

Perfetti, C. A., and Harris, L. N. (2013). Universal reading processes are modulated by language and writing system. Lang. Learn. Dev. 9, 296-316. doi: 10.1080/15475441.2013.813828

Perfetti, C. A., Nelson, J., Liu, Y., Fiez, J., and Tan, L.-H. (2010). "The neural bases of reading: universals and writing system variations," in The Neural Basis of Reading, eds P. Cornelissen, M. Kringelbach, and P. Hansen (New York, NY: Oxford University Press), 147-172.

Prakash, P., Rekha, D., Nigam, R., and Karanth, P. (1993). "Phonological awareness, orthography and literacy," in Literacy and Language Analysis, ed R. J. Scholes (Hillsdale, NJ: Lawrence Erlbaum Associates), 55-70.

Rao, C., Soni, S., and Chatterjee Singh, N. (2012). The case of the neglected alphasyllabary: orthographic processing in Devanagari. Brain Behav. Sci. 35, 302-303. doi: 10.1017/S0140525X12000313

Seidenberg, M. S. (2011). "Reading in different writing systems: one architecture, multiple solutions," in Dyslexia Across Languages: Orthography and the Brain-Gene-Behavior Link, eds P. McCardle, B. Miller, J. R. Lee, and O. J. L. Tzeng (Baltimore, MD: Paul H. Brookes), 146-168.

Share, D. L. (2014). Alphabetism in reading science. Front. Psychol. 5:752. doi: 10.3389/fpsyg. 2014.00752

Sircar, S., and Nag, S. (2013). "Akshara-syllable mappings in Bengali: a language-specific skill for reading," in South and South-East Asian Psycholinguistics, eds H. Winskell and P. Padakanayya (Cambridge: Cambridge University Press), 202-211. 
Vaid, J., and Gupta, A. (2002). Exploring word recognition in a semi-alphabetic script: the case of Devanagari. Brain Lang. 81, 679-690. doi: 10.1006/brln.2001.2556

Wijayathilake, M. A. D. K., and Parrila, R. (2014). Predictors of word reading skills in good and struggling readers in Sinhala. Writ. Syst. Res. 6, 120-131. doi: 10.1080/17586801.2013. 846844

Winskel, H., and Perea, M. (2014). Can parafovealon-foveal effects be obtained when reading an unspaced alphasyllabic script (Thai)? Writ. Syst. Res. 6, 94-104. doi: 10.1080/17586801.2013. 843440
Ziegler, J. C., and Goswami, U. (2005). Reading acquisition, developmental dyslexia, and skilled reading across languages: a psycholinguistic grain size theory. Psychol. Bull. 131, 3-29. doi: 10.1037/00332909.131.1.3

Conflict of Interest Statement: The author declares that the research was conducted in the absence of any commercial or financial relationships that could be construed as a potential conflict of interest.

Received: 26 May 2014; accepted: 20 July 2014; published online: 12 August 2014.
Citation: Nag S (2014) Alphabetism and the science of reading: from the perspective of the akshara languages. Front. Psychol. 5:866. doi: 10.3389/fpsyg.2014.00866

This article was submitted to Cognitive Science, a section of the journal Frontiers in Psychology.

Copyright (c) 2014 Nag. This is an open-access article distributed under the terms of the Creative Commons Attribution License (CC BY). The use, distribution or reproduction in other forums is permitted, provided the original author(s) or licensor are credited and that the original publication in this journal is cited, in accordance with accepted academic practice. No use, distribution or reproduction is permitted which does not comply with these terms. 